Session 3148

\title{
Great Progress, Great Divide: The Need for Evolution of the Recruitment Model for Women in Engineering
}

\author{
Jennifer Gilley and Joan Begolly \\ Penn State New Kensington
}

\begin{abstract}
Despite years of recruitment efforts, the percentage of engineering bachelor's degrees awarded to women in the U.S. still hovers at only $18 \%$, and the percentage of degrees awarded in engineering technology stands at $16 \%$. The question then remains, what keeps high school girls from choosing engineering or engineering technology as a potential career path? Or conversely, for those girls who do consider engineering and technology, what is motivating them to do so? We surveyed the participants in an on-campus outreach program at Penn State New Kensington entitled Females Interested in Reaching for Science, Technology, and Engineering (FIRSTE) to garner information about demographics, influences, and perceptions that may have enabled their consideration of a scientific/engineering career. To determine their uniqueness, we administered the same survey to a control group of college students in non-scientific and non-engineering fields. The differences in background influences between the two groups were subtler than predicted, but the perceptions of both groups about engineering were enlightening. We found that although great progress has been made in eliminating certain disadvantages that keep girls from entering the science and engineering pipeline, the great divide between girls and engineering remains due to a lack of familiarity with the nature and possibilities of engineering and engineering technology.
\end{abstract}

\section{Introduction}

\section{Low Number of Degrees Earned}

Between 1994 and 2001 the percentage of engineering bachelor's degrees awarded to women grew from $16 \%$ to $20 \%{ }^{1}$. While this growth is encouraging, it is occurring at a painfully slow pace and is partially due to a decrease in the number of men enrolling in engineering programs rather than a substantial increase in female enrollment. The numbers for engineering technology programs are even lower. The percentage of associate's degrees in engineering technology awarded to women in 2001 stands at only $16 \%$, an increase from 13\% in 1994 only because of a decline in male enrollment ${ }^{1}$. Over two decades of recruitment efforts, outreach programs, awareness-raising, and attempts to infuse women role models into elementary and secondary math and science education have done much for moving women into scientific fields, but neither engineering nor engineering technology has felt these effects the way other scientific fields have. Biological/life sciences is a particular success story with $57 \%$ of degrees now going to women. Other science fields still have a ways to go but are making progress: $41 \%$ of physical science 
degrees, for example, are now awarded to women ${ }^{1}$. Still, engineering and engineering technology degree attainment for women hovers at or below $20 \%$.

\section{Source of Problem}

The problem is not one of women switching majors or dropping out of the field once in college, but rather one of enrollment. According to a National Center for Education Statistics report in August 2000, longitudinal data showed that female students enrolled in science and engineering programs had a higher retention and completion rate than males in these programs ${ }^{2}$. The current raw data supports this. 17\% of first year students in engineering programs in 2002 were women, suggesting that a continuance of the current $20 \%$ female completion rate would have to be achieved through male attrition, with minimal dropouts among the women ${ }^{1}$. Thus, although reasons for women dropping out and switching majors in undergraduate engineering programs should be closely studied, it appears that the main leakage in the pipeline of women going into engineering and engineering technology careers occurs much earlier.

\section{Search for Answers}

What keeps college-bound high school girls from choosing engineering/technology as a potential career path? Conversely, for those girls who are choosing engineering/technology, what is enabling or motivating them to do so? Penn State New Kensington's FIRSTE Program (Females Interested in Reaching for Science, Technology, and Engineering) attempts to provide a positive intervention into the career consideration of high school girls toward science, engineering, and engineering technology careers, and past participants in this program were surveyed to provide data useful in answering these persistent questions.

\section{The Survey}

\section{Population Surveyed}

The Penn State New Kensington FIRSTE Program (Females Interested in Reaching for Science, Technology, and Engineering) is a 12-year-old outreach program targeted at potential collegebound ninth through eleventh grade females from high schools in the Penn State New Kensington service area. Girls with a demonstrated aptitude in math and science attend an overnight on-campus program that exposes them to a variety of high tech career fields, connects them with women employed in these fields, and provides them with hands-on experience in the following workshops: mechanical engineering technology, biomedical engineering technology, robotics, global positioning systems, and mechanical drafting with Autocad. Penn State offers both 4 year and 2 year degrees in engineering technology and serves as a feeder campus for the rest of the engineering degrees Penn State offers. The primary purpose of the program is to recruit girls into science, engineering, and engineering technology programs, preferably at Penn State New Kensington or Penn State in general. So far, of the 117 past participants eligible to attend college by Fall of 2003, 71\% had chosen engineering, engineering technology, or science majors as their field of study, $31 \%$ had chosen to attend Penn State, and 27\% of those had enrolled at Penn State New Kensington.

In order to attend the FIRSTE program, girls must apply and be accepted. Girls who have demonstrated skill in math and science are generally encouraged by their teachers or guidance 
counselors to apply. Girls who indicated that they were "undecided" about their career choice were given priority over girls who had already decided on a science, engineering, or technology career. This way these career options would be opened to girls who may not otherwise have had any exposure to them. Regardless of ultimate career choice, the fact that these girls applied to attend the FIRSTE program indicates that they were qualified and willing to at least consider scientific and engineering careers during the formative years of high school. This makes them an ideal group to study in order to determine possible background influences that may have brought them to that moment of opportunity.

\section{Survey Instrument}

A literature review was conducted to determine what questions should be included on the survey. Girls' abilities in, enjoyment of, and experience with math and science has long been identified as the gate keeping a larger portion of girls from entering scientific and engineering fields. Several studies have shown that girls' perceptions of their own abilities in math and science are the single largest predictor of whether or not they will consider these fields ${ }^{2,3,4,5}$. The literature exploring the issue of girls' math and science abilities has shown that girls' performance in math and science exceeds that of boys in the elementary grades ${ }^{6}$. In middle school, girls experience a well-documented drop in self-esteem and self-confidence ${ }^{7}$, that many researchers have correlated with a drop in the number of girls who take or are interested in the advanced math and science classes $^{6}$, thus precluding their entry into the pipeline for science and engineering careers. The latest findings however show that the gender gap in math and science performance in high school, at least at the level of coursetaking, seems to be nearly gone. At least two studies have indicated that the gender gap in coursetaking has closed in all areas except physics ${ }^{2,5}$, and one study showed that by 2002 , even physics had a $43 \%$ female enrollment ${ }^{8}$. Because the Penn State New Kensington service area includes large rural areas, it was decided to include questions about advanced course enrollment, and the gender parity in math and science classes to see if these findings held true for our population. Questions about enjoyment and ability regarding math and science were also included to measure their relationship to the choice of scientific or engineering careers.

In addition to math and science, a compilation of research studies yielded the following list of factors related to the likelihood of females choosing to enter an engineering or technological field: family income (socioeconomic status), self-confidence, role models, peer support, teaching methods, education, perceptions of engineering, and sex-role stereotypes ${ }^{9,10,11,12,13}$. Several studies particularly emphasized the importance of parental and teacher support in choosing these fields ${ }^{2,14,15,16}$. The National Center for Education Statistics organizes these factors into three broad categories: "family environment and support factors; student behavior factors such as attitudes, aspirations, and academic preparation; and

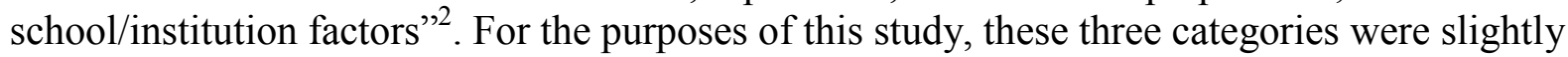
reorganized into the following: demographics, influences, and perceptions/attitudes. Demographics covered college major, family socioeconomic status, parent occupations, family birth order, geographical distribution, and their high school academic background. The influences section covered parents, teachers, friends, professionals, and open-ended encouraging and discouraging factors. Finally, the perceptions/attitudes section tested the girls' self-efficacy in math and science, awareness of any societal attitudes about women in engineering, and perceptions of the positive and negative aspects of going into a technology or engineering field. 


\section{Engineering Technology: Literature Review}

There have been few studies focused specifically on the recruitment and retention of women into engineering technology, but those that exist identify similar factors to those listed above in determining the recruitment of girls ${ }^{14,17,18,19}$. One study of female engineering technology students listed the following results: $31 \%$ had friends in their field, $46 \%$ had friends in other technical fields, $54 \%$ knew adults in technical fields, and 54\% thought female role models were important $^{17}$. The influence of peers, role models, and social networks are all covered in the survey instrument design for this study.

\section{Methodology}

The final survey instrument consisted of 24 questions identifying demographics, influences, and perceptions/attitudes that may have influenced the girls' receptivity to science, technology, or engineering careers. In order to get a glimpse of the most current social, cultural, and educational situation possible, we chose to survey only former FIRSTE participants who are currently enrolled in college, their formative years not being long behind them. This left us with a pool of 54 college-age women, 23 of whom ultimately participated in this survey ( $43 \%$ response rate). To test the uniqueness of their survey answers, we also administered the survey to a control group, consisting of 23 traditional age college women who are currently enrolled students at Penn State New Kensington, but are not majoring in a science or engineering field and never applied to or attended the FIRSTE program. The surveys were administered to the FIRSTE participants via phone calls and email, and response was encouraged with a \$10 study participant payment. Surveys were administered to the control group via in-person interview in the campus cafeteria and the same remuneration was offered.

\section{The Results}

\section{Demographics}

Of the 23 FIRSTE participant respondents, 9 were majoring in science, 6 were majoring in engineering, and 8 had chosen majors outside of science and engineering. The control group was made up of students in non-scientific and non-technical majors. Father's occupations were similar for both groups: $48 \%$ of the FIRSTE group's fathers had scientific or technical occupations, $39 \%$ for the control group. The results for mother's occupation showed a more suggestive result: the FIRSTE group showed $17 \%$ had mothers in scientific or technical occupations, the control group $0 \%$. While still relatively rare, it is evident that having a mother as a role model in these occupations, may have a large impact. Breakdown by socioeconomic class showed both groups to have the same basic makeup, with the majority middle class and a small percentage each of working class and upper middle class. The control group contained a larger percentage of participants from rural backgrounds than the FIRSTE group (43\% vs. 26\%), while the FIRSTE group contained a larger percentage of suburbanites (65\% vs. 52\%). 


\section{Influences}

Despite past researcher's hypotheses about a lack of female role models in math and science, this study showed that this is not the case, at least in our service area. 100\% of the FIRSTE group and $96 \%$ of the control group reported having had at least one female math/science teacher. The FIRSTE group had an average of 3.2 female math/science teachers each; the control group average was 2.3. Given that most high school students probably take one math and one science each year for a total of 8 classes, the ideal average would be 4 , but these averages were higher than expected. Both groups had access to women role models in these fields.

Our findings mirrored the research cited earlier stating that the gender gap in high school math and science classes has nearly closed. The majority of each group (FIRSTE 65\%; control $56 \%$ ) said that there was an even number of boys and girls in their math classes. Boys were predominant in 30\% of the FIRSTE group responses and 39\% of the control group, and girls were predominant in $13 \%$ of the FIRSTE group responses and $.04 \%$ of the control group. Given the body of research stating that boys outperformed girls consistently at the high school level of math and science in the $1980 \mathrm{~s}$, this is a significant testament to the work that has been done at deprogramming gendered tracks in high school. Numbers alone do not ensure equal treatment, of course. One study of parents teaching their kids showed that even though "there were no differences between girls and boys in their grades, interest, or self-efficacy in science...there was strong indication of differential treatment" 20 . This is an area of need for further study.

The majority of both groups had friends in high school who were considering scientific or technical careers (FIRSTE 61\%; control 74\%), and knew at least one scientist or engineer when they were growing up (FIRSTE 52\%; control 52\%). The relative similarity of the two groups indicates that the peer groups and social networks appeared to create no remarkable difference on the subject's career choices.

The most suggestive difference in influences between the groups, and therefore the strongest indicator of what caused the FIRSTE participants to become receptive to science and engineering, lay in high school teachers as mentors. For the FIRSTE group, 78\% said that they did have high school teachers who served as mentors, and $83 \%$ of those mentors were in math or science. In contrast, although $65 \%$ of the control group said that they had high school teachers who served as mentors, only $40 \%$ were in math or science. Still, perhaps $40 \%$ is an impressive number of math and science mentors for a group that, as far as is known, never even considered going into a science or technical field. This is a sign that support mechanisms are in place, but are not always having their intended effect on recruitment. This issue will resurface in the discussion on students' individual performance in math and science.

A similar finding in which there was a substantive difference between the two groups, but not quite as significant as expected, was in the area of encouraging factors. Asked to list factors that encouraged them to go into science, technology, or engineering, $61 \%$ of the FIRSTE group were able to do so, while only $35 \%$ of the control group did. Still, the fact that $35 \%$ of the control group were actively encouraged to consider a career in these areas shows that recruitment methods are getting out there, just not always having an effect. On the flip side, the same 
numbers from both groups listed specific discouraging factors (FIRSTE 30\%; control 30\%). In a 1994 study, 57\% of the undergraduates surveyed listed discouraging factors they had encountered in high $\mathrm{school}^{21}$. It is promising that in this study that percentage has dropped by almost half. It is however important to temper optimism about the success of recruitment methods with awareness that there are still responses such as "a male math teacher was really discouraging" and "the guys dominated, I felt intimidated."

\section{Perceptions/Attitudes}

One of the fundamental tenets of recruiting women into science and engineering has been that they must necessarily be good at and enjoy math and science, and that this is the secret key that will lead them down the science/engineering path. As stated earlier, the self-efficacy of girls (how they perceive their abilities) with regard to math and science is the most significant predictor of their career choice of science or engineering. Additionally, because science and engineering are seen as demanding disciplines, only girls who are high achievers are generally targeted for recruitment. This study shows evidence of this in the academic backgrounds of our study participants. In the FIRSTE group, $87 \%$ had taken advanced placement classes in high school, with an average of 3.6 subjects each, and $83 \%$ had taken an advanced math or science class. In the control group, only $48 \%$ had taken advanced placement classes, with an average of 2 classes each, and only $30 \%$ had taken an advanced math or science class. It might be expected, therefore, that the control group would have significantly less confidence in their math and science skills. This, however, did not turn out to be the case.

When asked if they considered themselves to be good at math or science, $100 \%$ of the FIRSTE group said that they were either good or average, and $70 \%$ of the control group did as well. Although there is a $30 \%$ difference here, it is far smaller than expected, given that only $30 \%$ of the control group had taken advanced math and science classes, the fact that from middle school on girls have lower self-esteem about their abilities in general, and the influence of the societal belief that girls are not as good as boys in math and science. We also asked the two groups if they enjoy math and science; $96 \%$ of the FIRSTE group said they enjoy either math or science or both, and $56 \%$ of the control group said the same. This does represent a significant difference between the two groups, but the numbers for the control group were far higher than expected. It was at this point in the research that the initial question began to expand. In addition to determining what motivated the FIRSTE participants to consider science and engineering careers, it became necessary to wonder why the control group women were NOT motivated to do so. Since they turned out to have much the same background influences as the FIRSTE group, the usual smoking guns are not present. Thom et al suggest that "efforts to provide young women better math and science backgrounds may make up for previous generation's shortfalls, but it does little to address why women should be interested in a math, science, or technical study path" 22 . Isaacs agrees that "recruiting efforts are ...directed toward encouraging girls to study math and science, but these efforts are focused on the wrong problem" $"$. As progress is made in equalizing the background influences on boys and girls, it is becoming apparent that there is a far more complex set of issues at stake, especially when it comes to engineering. 
When asked if they were aware of any attitudes about girls going into science, technology or engineering, 30\% of the FIRSTE group listed negative attitudes, 39\% said they were not aware of any attitudes, and 30\% listed positive attitudes. The control group, in contrast, mostly said they were not aware of any attitudes (83\%), and 17\% listed negative attitudes. The FIRSTE group seemed hyperaware of the reality that girls and women are in the minority in these occupations, but many of them saw that as a positive motivation for going into these fields, rather than a discouragement. In fact, of the 6 women who ended up in the engineering field, 4 of them listed needing more women in the field as a positive criterion for going into it. Given a lack of other obvious motivators besides having high school mentors in math and science, it almost seems as if this was an overriding reason of why they chose to go into it. This is a happy but somewhat tenuous side effect of the increasingly widespread nature of recruitment efforts to get women into the scientific pipeline. There needs to be a far more concrete and full realized set of motivating factors than just knowing that women are needed. The amorphous nature of girls' knowledge of what is entailed in scientific and particularly engineering professions comes out even more clearly in the final two survey questions.

When asked what might be positive about going into a science, technology, or engineering field, the answers for both groups could be broken down into six categories: interesting/challenging, money, making a difference, prestige, good job opportunities, and being in the minority as a woman in the professions. Respondents could list more than one item, so the numbers do not add up to 23 . See figure 1 for the numeric breakdown.

\begin{tabular}{|l|l|l|}
\hline Positives & FIRSTE & Control \\
\hline Interesting/challenging & 7 & 10 \\
\hline Good job opportunities & 6 & 4 \\
\hline Money & 6 & 5 \\
\hline Make a difference & 4 & 1 \\
\hline Prestige & 5 & 2 \\
\hline Being a woman/minority & 5 & 3 \\
\hline
\end{tabular}

Figure 1. Positives about going into a scientific or engineering field

While it may be gratifying to see so many people say that these fields are interesting, the issue becomes much thornier when it becomes apparent that so many of the control group think they are interesting, felt they were good at math and science, and enjoyed math and science, yet did not choose these career fields. A clue to this mystery lies partially in looking closer at the subtleties of their perception of interesting. Most of these answers included phrases like "challenging," "constantly changing," "advancing," and "intellectual." These words indicate an underlying anxiety that was fully borne out in the responses to the question about negatives. In a 1998 study, Blaisdell's findings echoed this phenomenon: "The more rewards a student believed a career in engineering would bring them, the less likely they were to indicate an intention to major in engineering" 24 . She concludes that they considered it to be an unachievable goal. 
The overwhelming answer to the question "what do you think might be negative about going into a science, technology, or engineering field" was that such a course of study is "really difficult." Figure 2 shows the other answers. Again, more than one response was possible, so the numbers do not add up to 23 .

\begin{tabular}{|l|l|l|}
\hline Negatives & FIRSTE & Control \\
\hline Really difficult & 10 & 12 \\
\hline Sexist attitudes & 6 & 2 \\
\hline Finding a job & 1 & 2 \\
\hline Boring & 3 & 3 \\
\hline Competitive nature & 1 & 0 \\
\hline Hard to have a family & 0 & 1 \\
\hline
\end{tabular}

Figure 2. Negatives about going into a scientific or engineering field

According to Thom et al, "image and fear of failure are reported in personal interviews and pilot studies as being the strongest factors preventing young women from entering a technical field"22. Given that difficulty was the most popular answer even from the FIRSTE group, who were very academically prepared, and that women now make up $43 \%$ of medical degrees awarded, which is certainly considered a "difficult" course of study, it seems that "difficulty" is a very special animal when referring to engineering. The image of difficulty in relation to the profession of engineering seems to stem from a general ignorance about what engineering is, including its larger purpose. According to a 2002 study of female participants in an engineering outreach program "less than one-third of the workshop participants were able to correctly describe engineering or what an engineer does" $"$. Medicine may be difficult, but people understand what the goal is and can therefore struggle through by holding on to the vision of the larger purpose.

\section{The Great Divide}

While the results of this survey have suggested that great progress has been made in ensuring that girls have equal access to the science and engineering pipeline in middle school and high school (although much more needs to be done), it is evident that this progress has not made a significant impact on the flow into that pipeline, at least in terms of engineering or engineering technology. The progress did pave the way for girls into the life sciences, but the valve to the engineering pipeline remains firmly closed. Girls who are adequately prepared to enter it are simply choosing not to do so. The salient question may be "how much do women really know about the engineering profession before they reject it" ${ }^{23}$ ? If women are not familiar with the nature of engineering or engineering technology, it is easy to see why they might find the profession interesting only in an abstract, anxiety-producing way. This lack of a real and engaging interest in, and knowledge about, the fields of engineering and engineering technology is creating a great divide between the pipeline and the high school girls who could otherwise fruitfully enter. It is imperative, therefore, that the next generation of recruitment strategies turns 
to defining very publicly what engineering and engineering technology are, improving the public image of engineers and engineering technologists, de-emphasizing the equation of pure math and science with engineering in favor of practical examples more conducive to engineering technology, and a deconstruction of engineering's mythic reputation of "difficulty."

\section{Bridging the Great Divide: a Recruitment Plan}

A 1998 Harris poll reported that $61 \%$ of Americans do not think they are well informed about engineers and engineering, and $78 \%$ of American women feel this way ${ }^{23}$. Engineering is fundamentally about solving problems to make things better. Creativity, communication skills, and a drive to improve the lives of humans or the environment are just as necessary in a good engineer as math and science skills. In one study, females asked to rate the most important factors in career choice rated the factor "contribution to society" more highly than males did" 25 A good recruitment slogan therefore might be: "engineering/technology is for those who love to solve problems and improve quality of life" rather than the traditional "engineering/technology is for those who love math and science." Advertised in this way, the qualities of a good engineer/technologist would seem a lot closer to girls' self-concepts and, when coupled with practical examples, would also give them a big picture of what engineering/technology is all about. According to one study, girls' concepts of what good science students were like tended to be far removed from their self-concepts. Since changing the way girls are socialized to think about themselves seems too large a job for engineering recruiters, it was determined that changing common perceptions of science and science students would be far more effective and would also lower the gap between self-image and image of science and engineering for both boys and girls ${ }^{26}$.

In two studies specific to engineering technology, Flowers notes that technology education in high school evolved from industrial arts and frequently takes place in dirty "shop" classrooms that are highly socialized to be "male" spaces ${ }^{14,19}$. In addition, technology education students frequently make things like gun racks and drag racers that are clearly malestereotypical. More attention to professional laboratory space and gender-free assignments might improve the entry of girls into the engineering technology pipeline through technology education in middle or high school, as well as broadening the popular definition of technology.

Zywno et al note that "engineering is perceived as a technical, often solitary pursuit, in which one works with machines rather than people" 27 . The only way to counteract this notion is with a huge education campaign, the likes of which have not been seen since the dropping of propaganda from planes onto unsuspecting populaces. Starting in $5^{\text {th }}$ or $6^{\text {th }}$ grade, engineers and engineering technologists need to be invited into all of the science classrooms to talk about the nature of their jobs and what they are really like. Preferably, different types of engineers could be featured each year to properly display the wide variety of ways in which problems can be solved and everyday living improved. Stressing the creativity, excitement of success, and humanitarian aspect of engineering would be particularly fruitful. As Isaacs suggests, having a popular television show about the drama and intrigue of engineering on par with what CSI did for forensic science would be an enormous boon ${ }^{23}$. But until that happens, efforts could be made to ensure that all guidance counselors are fully educated about the nature and variety of engineering and technology jobs and encouraged to stress the importance of qualities beyond just skill in 
math and science when suggesting these careers. A third way to get the message to students would be to encourage field trips to local engineering sites so they can see the practical outcome of what engineers do. The FIRSTE program has had much success with these tactics.

Another goal of the FIRSTE program is to change the stereotypical images of engineers that girls may have, again by inviting local women engineers to come and speak. These women belie the popular perception of the engineer as Dilbert, with the thick glasses, pocket protector, and cubicle lifestyle. It has been shown that girls also anticipate a lack of support, communication, and camaraderie in technical careers (remember the survey participant that listed "competitive nature" as a negative?) that keeps them from being attracted to those careers. It takes role models to show that femininity, supportiveness, courtesy, and camaraderie are not incompatible with the field of engineering ${ }^{22}$.

\section{Conclusions}

Although this study set out to discover what factors had resulted in leading FIRSTE program participants to considering science and engineering career paths, the snapshot of background influences for the FIRSTE group and the control group were not as dissimilar as expected. In fact, the only influence that really stood out for the FIRSTE group was the presence of a high school teacher in math or science who served as a mentor. It appears that some suspected red flags, such as a lack of female math and science teachers, girls' sense of self-efficacy at math and science, and the presence of discouraging attitudes about girls in science and engineering are all factors whose importance is diminishing. This is not to say that efforts to remedy these issues are complete, just that they are making progress. In the meantime, the matriculation of girls into engineering and engineering technology programs is not reflecting this progress, which points to other factors such as interest in and understanding of engineering. It is therefore time to further revolutionize the approach to recruiting women by defining what engineering and technology are early on in a student's education and emphasizing those qualities that are more likely to fit with girls' self-image such as creativity and communication skills. This will benefit the profession as well as begin to bridge the great divide that currently exists between the profession and the women whose skills and talents are so desperately needed.

\section{References}

${ }^{1}$ National Science Foundation. 2004. Women, minorities, and persons with disabilities in science and engineering. http://www.nsf.gov/sbe/srs/wmpd/sex.htm> Accessed 2004 Dec 21.

${ }^{2}$ Huang G, Taddese N, Walter E. 2000. Entry and persistence of women and minorities in college science and engineering education. $<$ http://nces.ed.gov/pubs2000/2000601.pdf > Accessed 2004 Dec 12.

${ }^{3}$ Chapman A. A great balancing act: equitable education for girls and boys. Washington, D.C.: National Association of Independent Schools; 1997.

${ }^{4}$ Vetter BM. Myths and realities of women's progress in the sciences, mathematics, and engineering. In: Davis $\mathrm{C}$ et al, editors. The equity equation: fostering the advancement of women in the sciences, mathematics, and engineering. San Francisco: Jossey-Bass; 1996. p.29-56. 
${ }^{5}$ Yauch CA. Majoring in engineering: a study of gender differences. Journal of Women and Minorities in Science and Engineering 1999;5:183-205.

${ }^{6}$ Yee M. Rebuilding the pipeline of women in engineering. 2002 WEPAN Conference Proceedings; 2002 Jun 811; San Juan, Puerto Rico: Women in Engineering Programs \& Advocates Network; 2002.

${ }^{7}$ American Association of University Women. How schools shortchange girls: the AAUW report. New York: Marlowe \& Co.; 1995.

${ }^{8}$ Koppel NB, Cano RM, Heyman SB. An attractive engineering option for girls. $32^{\text {nd }}$ ASEE/IEEE Frontiers in Education Conference; 2002 Nov 6-9; Boston, Mass.: Frontiers in Education; 2002. p. F1C-2-7.

${ }^{9}$ Kahle JB. Opportunities and obstacles: science education in the schools. In: Davis C et al, editors. The equity equation: fostering the advancement of women in the sciences, mathematics, and engineering. San Francisco: Jossey-Bass; 1996. p.57-95.

${ }^{10}$ Blaisdell S. Predictors of women's entry into engineering: why academic preparation is not sufficient. Women in Engineering Conference; 1998 Jun 14-16; Seattle, Wash.: Women in Engineering Programs \& Advocates Network; 1998. p. 31-37.

${ }^{11}$ Anderson L, Gilbride K. Gender bias towards engineering careers: does it still exist? 2002 WEPAN Conference Proceedings; 2002 Jun 8-11; San Juan, Puerto Rico: Women in Engineering Programs \& Advocates Network; 2002.

${ }^{12}$ Kauser Jahan PE, Sukumaran B, Head L, Keil ZO. AWE: a workshop for attracting middle school girls to engineering. 2000 WEPAN National Conference; 2000 Jun 25-27; Washington, D.C.: Women in Engineering Programs \& Advocates Network; p. 63-69.

${ }^{13}$ Watson K, Rinehart J, Draughn T, Algert N. Accelerating the growth of the participation of women in engineering. 2001 Joint NAMEPA/WEPAN National Conference; 2001 Apr 21-24; Alexandria, VA: Women in Engineering Programs \& Advocates Network; p. 196-201.

${ }^{14}$ Flowers J. Women in technology: increasing the number of female teachers and students. Women in Engineering Conference; 1995 Jun 4-6; Washington, D.C.: Women in Engineering Program Advocates Network; 1995. p. 161-166.

${ }^{15}$ Evans MA, Hinders S, Kanengieter H. A study of women engineering and science undergraduates. Women in Engineering Conference; 1993 May 23-25; Washington, D.C.: Women in Engineering Program Advocates Network; 1993. p. 225-230.

${ }^{16}$ Lazarus BB, Nair I, Palmgren C. Beyond anecdote: research on women in engineering. Women in Engineering Conference; 1992 May 31-Jun 2; Washington, D.C.: Women in Engineering Program Advocates Network; 1992. p.23-26.

${ }^{17}$ Garrod SAR, Taber MR. Counseling women in engineering technology to prepare them for the future. Journal of Engineering Technology 1991;8(1):20-25.

${ }^{18}$ Gallaher J, Pearson F. Women's perception of the climate in engineering technology programs. Journal of Engineering Education, 2000;89:309-314+388-391.

${ }^{19}$ Flowers J. Curriculum, methods, and males: problems and solutions to low female enrollment in college and pre-college technological courses. Women in Engineering Conference; 1998 Jun 14-16; Seattle, Wash.: Women in Engineering Programs \& Advocates Network; 1998. p. 257-262.

${ }^{20}$ Tenenbaum HR, Leaper C. Parent-child conversations about science: the socialization of gender inequities? Developmental Psychology 2003;39(1):34-47.

${ }^{21}$ Cosgrove CR, Blaisdell S, Anderson MR. A climate survey and needs assessment. Women in Engineering Conference; 1994 Jun 5-7; Washington, D.C.: Women in Engineering Program Advocates Network; 1994.

${ }^{22}$ Thom M, Pickering M, Thompson RE. Understanding the barriers to recruiting women in engineering and technology programs; 2002 Nov 6-9; Boston, Mass.: Frontiers in Education; 2002. p. F4C1-6.

${ }^{23}$ Isaacs B. Mystery of the missing women engineers: A solution. Journal of Professional Issues in Engineering Education and Practice 2001;127:85-91.

${ }^{24}$ Blaisdell S. Predictors of women's entry into engineering: Why academic preparation is not sufficient. Proceedings of the 1998 Frontiers in Education Conference; 1998;221-225.

${ }^{25}$ Vickers M, Ching HL, Dean CB. Do science programs make a difference? Proceedings, More Than Just Numbers Conference, University of New Brunswick, Fredericton, NB, Canada E3B 5A3: 83-87.

${ }^{26}$ Lee JD. Which kids can become scientists? Effects of gender, self-concepts, and perceptions of scientists. Social Psychology Quarterly 1998; 61(3): 199-219.

${ }^{27}$ Zywno MS, Gilbride KA, Hiscocks PD, Whalen JK, Kennedy DS. Attracting women into engineering - a case study. IEEE Transactions on Education 1999;42(4): 364-370. 
JENNIFER GILLEY is the Head Librarian at Penn State New Kensington. Her research focus is gender and technology.

JOAN BEGOLLY is a Senior Instructor of Engineering at Penn State New Kensington and a Co-Director of the FIRSTE Program to recruit Females Interested in Reaching for Science, Technology, and Engineering. 